\title{
INTERPRETACIÓN TELEOLÓGICA DE LA CONSTITUCIÓN
}

\author{
POR \\ ANTONIO TORRES DEL MORAL \\ Catedrático de Derecho Constitucional
}

\section{ORDENAMIENTO JURÍDICO E INTERPRETACIÓN CONSTITUCIONAL}

Es ya un valor entendido que el problema de la interpretación es, seguramente, uno de los centrales de la ciencia del Derecho Constitucional, porque, a la postre, la norma dice lo que los que la interpretamos decimos que dice. Igualmente, se han recordado hasta la saciedad los métodos savignyanos de la interpretación y su multiplicada complejidad en la Teoría jurídica de nuestros días.

Las reflexiones siguientes quieren ceñirse a la interpretación finalista o teleológica de la Constitución, que tantas veces nos orienta sobre el verdadero sentido de un precepto cuando, perplejos ante su dicción literal, sus antecedentes históricos y su inserción sistemática en un capítulo o un título de la norma suprema, nos preguntamos qué es lo que en realidad se pretende con tal precepto. No se trata tanto, aunque también, de las clásicas preguntas sobre la voluntas constitutionis o la voluntas constituentis, sino, más radicalmente, cuál es el cometido o función de tal precepto en el conjunto normativo en el que se instala o en la institución que contribuye a regular jurídicamente.

Porque el Derecho no es un simple agregado de partículas normativas. Las normas son creadas y aplicadas no de forma atomizada, sino interrelacionada, formando, como dice J. A. SANTAMARía, conjuntos y subconjuntos, estructuras, subsistemas, los cuales se integran, a su 
vez, en una estructura superior y unitaria: el sistema normativo u Ordenamiento jurídico, en el que, como dice F. BALAGUER, tienen cabida también principios, valores, relaciones jurídicas e instituciones. El Ordenamiento jurídico, dice L. DíEZ-PICAZO, comporta dentro de sí una trabazón o urdimbre, lo que presupone unas normas ordenadas (jerarquizadas, compatibilizadas) y, en definitiva, una exigible coherencia, como se corresponde a un sistema dinámico, como lo calificó IHERING. Solamente así el Ordenamiento jurídico puede ser uno, pleno y coherente (no se trata de que el Ordenamiento sea completo en el sentido de que lo tiene todo regulado, sino en el de que, aun no siendo así, ofrece posibilidades de solución de todo problema jurídico que se produce en su seno); y sólo así puede desempeñar sus funciones de identificar las normas vigentes en cada instante, atribuirles su más preciso significado a través precisamente de la interpretación y dotarlas de eficacia (J. A. SANTAMARÍA).

Añadamos que sólo de esta manera pueden superarse las posibles antinomias que se nos presenten, que no han de faltar nunca, haciendo factible así la tarea de depuración y coherencia del Ordenamiento, tarea facilitada por los principios jurídicos, algunos de los cuales han merecido su mención expresa por la Constitución (española): jerarquía normativa, prevalencia y supletoriedad del Derecho producido por el poder central...; y otros son fácilmente deducibles de su articulado: competencia, especialidad de procedimiento, etcétera.

Así, pues, el Ordenamiento, como totalidad normativa organizada, estructurada, con muchas subestructuras y subordenamientos menores, ha de tener, sin embargo, una unidad de sentido para poder ser eficaz. Y esa unidad de sentido la proporciona la Constitución debidamente interpretada a fin de que, como ha puesto de relieve A. E. PÉREZ LUÑo, ponga de manifiesto su coherencia, su concordancia práctica y la integración de sus elementos para, de esa manera, maximizar la eficacia de sus mandatos sin distorsionar su contenido ${ }^{1}$. La interpretación constitucional debe buscar la compatibilidad entre sus preceptos y principios, los cuales se informan recíprocamente ${ }^{2}$, sin que ninguno de ellos pueda ser sobrepuesto a otro ${ }^{3}$, dice el Tribunal Constitucional.

Es así porque en la Constitución se proclaman los valores superiores, las opciones políticas fundamentales, los principios jurídicos que vertebran las instituciones, las declaraciones y reconocimientos que

1 Pérez Luño, A. E., Derechos humanos, Estado de Derecho y Constitución, Tecnos, Madrid, 1984, pp. 276-278.

2 STC 26/1987, de 27 de febrero.

3 STC 19/1987, de 17 de febrero. 
perfilan el régimen, las garantías de los derechos y del funcionamiento institucional, las reglas de creación jurídica, etcétera. En suma, la Constitución proporciona un sentido unitario para todo el sistema político, jurídico y económico, en el que se incluye la misma posibilidad de cambio. Más allá de esta unidad de sentido y de los procedimientos establecidos para el cambio está lo inconstitucional, lo ilegítimo para el Ordenamiento jurídico español.

Como dice el propio Tribunal, la Constitución, a partir de la proclamación del artículo 1.1, debe ser "un sistema coherente en el que todos sus contenidos encuentren el espacio y la eficacia que el constituyente quiso otorgarles»" ${ }^{4}$. La Constitución forma un todo "en el que cada precepto encuentra su sentido pleno valorándolo con los demás; es decir, de acuerdo con una interpretación sistemática» ${ }^{5}$, armónica y unitaria, sin subordinar unos contenidos a otros, porque todos son «expresiones y soporte de un mismo y único modelo de comunidad política» ${ }^{6}$.

\section{LA INTERPRETACIÓN FINALISTA COMO PRINCIPIO TÁCITO DE INTERPRETACIÓN DE LA CONSTITUCIÓN ESPAÑOLA}

Por lo que a este trabajo importa, esa interpretación sistemática, en su sentido más pleno, incluye los otros tres modelos savignyanos y el elemento teleológico, pues los fines, los valores y las opciones políticas también forman parte de la Constitución, están en su articulado, informan sus preceptos: "La Constitución — dice su supremo intérprete- incorpora un sistema de valores cuya observancia requiere una interpretación finalista de la Norma fundamental ${ }^{7}$, que busque, además, la proporcionalidad entre los actos y sus consecuencias ${ }^{8}$.

Por otra parte, uno de los principios tácitos antes aludidos en el epígrafe anterior, pero casi omnipresente en la Constitución es este de la interpretación finalista de los preceptos, o, al menos, de algunos de ellos.

Así, cuando el artículo 1.1 identifica los valores superiores del Ordenamiento jurídico, nos está invitando a interpretar la Constitución, toda ella, con la mirada puesta en la maximización de dichos valores: li-

4 STC 206/1992, de 27 de noviembre.

5 SSTC 6/1983, de 4 de febrero; 227/1988, de 29 de noviembre; 168/1993, de 28 de mayo, y 179/1994, de 16 de junio.

6 STC 206/1992, citada.

7 STC 18/1981, de 8 de junio (cursivas mías).

8 STC 24/1990, de 15 de febrero. 
bertad, justicia, igualdad y pluralismo político. De manera que, de dos interpretaciones, si una redunda en un cierto menoscabo de tales valores, o de alguno de ellos, y otra en su concepción amplia, debe ser preferida la segunda.

Pero, además, poniendo en relación lo anterior con la dicción del mismo precepto de que España se constituye en un Estado social y democrático de Derecho, afirmando además, en su apartado segundo, que la soberanía reside en el pueblo, del que emanan los poderes del Estado, la Constitución está haciendo una clara definición democrática del régimen que instaura. De donde se puede extraer un principio fundamental de interpretación de toda la norma suprema, y aun de todo el Ordenamiento jurídico: el principio democrático, que unas veces juega en sentido procedimental (unos procedimientos son más democráticos que otros o redundan en un funcionamiento más democrático de una institución) y otras veces juega en sentido teleológico, por cuanto tiene como telos la profundización democrática del sistema político y el alcance de cotas más altas de esos referidos valores superiores del Ordenamiento.

En similar sentido podemos pronunciarnos respecto del artículo 10.1, que hace de la dignidad de la persona, de sus derechos inherentes, del libre desarrollo de su personalidad y del respeto a la ley el fundamento del orden político y de la paz social, esto es, del régimen instaurado. Cierto que dice fundamento y no valores ni fines estatales, pero, como decía ARISTÓTELES, el fin, la causa final, forma parte de la esencia de las cosas; luego está en su propio fundamento.

De otro lado, aunque el texto supremo español no alude a su elaboración consensuada, es evidente que así se hizo, con lo que dejó una impronta de pacto político muy marcada. No es que unas constituciones sean absolutamente consensuadas, otras absolutamente impuestas y otras, en fin, totalmente otorgadas. Estos son sólo modelos de análisis que no se dan puros en la realidad histórica. Nunca una fuerza política ha sido tan poderosa y libérrima que haya podido imponer su nuda voluntad, aunque sólo sea por condicionamientos internacionales. Nunca ha sido tan generosa y desprendida que haya otorgado derechos y libertades si no veía necesidad o conveniencia en ello. $Y$ nunca las fuerzas sociales y políticas han estado tan equilibradas que no hayan prevalecido unas sobre otras a la hora de la negociación. Dicho de otra manera: toda Constitución es resultado de las fuerzas presentes y actuantes; y éstas actúan, por necesidad, conveniencia o cálculo, bien negociando, bien tratando de imponer sus criterios. La diferencia entre una y otra vía es, pues, de grado, de donde deriva el 
nivel de aceptación del texto resultante entre tales fuerzas y entre los ciudadanos.

La Constitución española fue consensuada, sí, pero no partiendo de cero, sino de los datos sociales, económicos y políticos que ofrecía el bienio constituyente. Estos datos condicionaban evidentemente algunas de las opciones constitucionales más definitorias del régimen que estaba construyendo. Así y todo, no es menos evidente que el resultado podía haber sido distinto de haberlo dejado a la libre energía de las fuerzas actuantes o latentes. Algo, por tanto, ha tenido que ver la prudencia política en ese resultado final y en el grado de aceptación que la Constitución ha logrado.

De manera que, si toda Constitución normativa y democrática es, y no puede dejar de ser, un pacto entre las fuerzas que están en tensión dialéctica acerca de los valores fundamentales con los que la sociedad quiere vivir y acerca de las reglas del juego social, político y económico con las que quiere operar, la Constitución española lo es plenamente, incluso, como hemos apuntado, por el método seguido durante el proceso constituyente. Este pacto juega un papel importantísimo de integración de dichas fuerzas, así como de los diversos territorios, en el régimen instaurado.

Huelga decir entonces que toda la interpretación constitucional queda informada por la idea de pacto, de manera que cuando un eventual sentido de un precepto o de un conjunto normativo puede redundar en una relajación (nada digamos si es una ruptura) del pacto político substante, debe ser rechazado por contravenir el sentido hondo de pacto, de consenso, de acuerdo fundamental en que consiste nuestra Constitución. He aquí, por consiguiente, otra vez teleológicamente orientada la interpretación constitucional entre nosotros.

En fin, en otras ocasiones se puede extraer igual conclusión de la textura normativa del precepto constitucional de que se trate. Así, por ejemplo, cuando una institución ha sido creada o recreada por la Constitución con un cometido funcional determinado, la interpretación de su actividad, de los preceptos de la ley de desarrollo que la regule y de los problemas o conflictos que pueda tener en el devenir constitucional, en lo que podríamos denominar Constitución realmente vivida, tiene necesariamente que pasar por el tamiz de la finalidad a la que la ley de leyes ha dedicado tal órgano o institución. Así, por ejemplo, cuando el artículo 54 constitucional atribuye al Defensor del Pueblo la misión de "la defensa de los derechos comprendidos en este Título" (el Título primero), hemos de interpretar sus funciones en tal clave y no en otra (además, en este caso lo dice expresamente la Constitución: "a cuyo 
efecto - dice el precepto- podrá supervisar la actividad de la Administración, dando cuenta a las Cortes Generales"). ¿Puede entonces el Defensor del Pueblo supervisar la actividad administrativa? Evidentemente, sí, pero sólo para la defensa de los derechos de los ciudadanos, no para cualesquiera otros fines. ¿Puede informar a las Cortes Generales? Respuesta idéntica: no puede hacerlo si no es con la finalidad de defender los derechos del Título I constitucional.

Ejemplo segundo: los dos apartados del artículo 131 de la Constitución regulan el procedimiento de elaboración y aprobación de la planificación general de la economía (algo que, dado el pensamiento único reinante, parece de mala educación mentar siquiera). Pues bien, el inciso final dice: "A tal fin, se constituirá un Consejo, cuya composición y funciones se desarrollarán por ley" (cursiva mía). La doctrina discrepa acerca de si el Consejo Económico y Social creado por la Ley 21/1991, de 17 de junio, es este del artículo 131, o no. Si lo es ${ }^{9}$, se ha creado a sabiendas de que el fin explícitamente mencionado por la Constitución no le va a ocupar ni un minuto de su actuación, lo que parece incoherente con la interpretación finalista. Pero si no lo es y se fuera a hacer una planificación de tales características (hipótesis que, por lo antes dicho, puede ser calificada de irreal, por lo menos durante los próximos veinte años, lo mismo que ha permanecido inédita otros veinticinco), tendría que crearse ese Consejo de la Planificación; y entonces ya parecen demasiados Consejos, contra lo que nos dicta otro principio interpretativo, conforme al cual, de dos interpretaciones plausibles, hemos de acogernos a la más sencilla. ¿Son plausibles las dos interpretaciones expuestas? No nos pronunciemos ahora, porque este estudio no se propone dirimir pleitos doctrinales laterales; baste con dejar constancia de que la idea de fin, de un fin adscrito a una institución, se encuentra en nuestra Constitución, y no una vez sola. Al final, se ha entendido que, aunque no se vaya a planificar, es útil contar con un Consejo Económico y Social, y si alguna vez se planifica, ya se cuenta con él a tal fin. Se trata de una lectura algo alambicada y más política que jurídica, pero tampoco parece insensata.

En fin, por cerrar este epígrafe, observemos que el artículo 124 de la Constitución asigna como misión del Ministerio Fiscal promover la acción de la justicia en defensa de la legalidad, etc. El término misión tiene algo de finalidad y otro tanto de competencia, precisamente la competencia propia para cumplir dicha finalidad. Lo que significa, a todas

9 Es favorable a esta interpretación Gutiérrez Nogueroles, A., El Consejo Económico y Social, UNED, Madrid, 2004. 
luces, que el Ministerio Fiscal no puede separarse de esa misión ni actuar en ámbitos diferentes ni de manera disconforme con ella.

De manera que, según estamos comprobando, la interpretación finalista se impone en determinadas ocasiones.

Pero es igualmente exigible dicha interpretación en los demás sectores del Ordenamiento constitucional (algunos de cuyos ejemplos hemos esbozado más arriba), cuales son las relaciones Gobierno-Cortes, el Estado autonómico y un etcétera muy amplio. Así, el Tribunal Constitucional, refiriéndose a este último asunto de la organización territorial española, ha establecido que, habiendo como hay muchas competencias compartidas por el poder central y los autonómicos, debe buscarse la finalidad de cada precepto pertinente para identificar al titular de la facultad concreta controvertida ${ }^{10}$.

A la postre, la interpretación teleológica de las normas constitucionales exige que, junto a la finalidad de la norma, se busque el telos de la propia Constitución, que no es otro que la creación y mantenimiento de un orden abierto a todas las posibilidades respetuosas de la dignidad humana y de la libertad, y que no impida la alternativa política ( $F$. RUBIO LLORENTE). A ese todo normativo, presidido por unos valores que le confieren unidad de sentido, se deben acomodar todas las demás piezas del Ordenamiento.

\section{MANDATOS A LOS PODERES PÚBLICOS, PROCEDIMIENTO LEGISLATIVO Y SENTENCIAS INTERPRETATIVAS}

\subsection{Mandatos a los poderes públicos}

Existen en la Constitución muchos preceptos cuyo contenido son mandatos que los poderes públicos deben materializar, o intentarlo al menos. Piénsese en los que distribuyen las clásicas funciones estatales entre los no menos clásicos poderes, o los que confieren las atribuciones del Tribunal Constitucional. Estos preceptos expresan una finalidad de división de poderes, conforme a la cual deben ser interpretados.

Hay otros mandatos a los poderes públicos de los que nos ocuparemos más adelante, cuando tratemos la interpretación finalista en el procedimiento legislativo, dentro de este mismo epígrafe.

Pero quiero hacer referencia especial, aunque breve, al artículo 53.3, el cual ordena: «El reconocimiento, el respeto y la protección de los

10 Cfr., por todas, STC 197/1996, de 28 de noviembre. 
principios reconocidos en el Capítulo tercero informará la legislación positiva, la práctica judicial y la actuación de los poderes públicos..." Si traducimos la última y equívoca expresión "poderes públicos" por Poder Ejecutivo (y Administración), el mandato se dirige a los tres clásicos poderes como finalidad principal de toda su actuación. Lo que viene a significar un plus en favor de la normatividad de dichos principios (que la doctrina, en general, no considera derechos, sino simples declaraciones programáticas), y puede decirse que cualquier actuación del Gobierno, de las Cortes o del Poder Judicial no inspirada en ellos es inconstitucional. Lo difícil es la prueba, dada la elasticidad conceptual de tales principios y que, además, en buena medida, dependen de las posibilidades presupuestarias, y éstas son, casi por definición, siempre escasas.

\subsection{El procedimiento legislativo}

El artículo 28.1 de la Ley Orgánica del Tribunal Constitucional precisa que la conformidad o disconformidad de las normas con rango, valor o fuerza de ley con la Constitución se apreciará considerando, además de los preceptos constitucionales, las leyes que delimitan las competencias del Estado (poder central) y de las Comunidades Autónomas, o que regulen o armonicen el ejercicio de las competencias de estas últimas. Igualmente hay que tener en cuenta otras normas que regulan el procedimiento de producción de normas con rango de ley. $Y$ aunque dicha Ley Orgánica no menciona entre éstas los reglamentos parlamentarios, sí lo ha hecho el Tribunal Constitucional en el ejercicio de su función de intérprete supremo de la Constitución; tanto los de las dos Cámaras centrales (Congreso y Senado) como los de los Parlamentos autonómicos. Es lo que se denomina bloque de la constitucionalidad.

Ambos tipos de normas prolongan la voluntas constitutionis, que en este caso es tanto como decir la finalidad perseguida por la Constitución en esos dos tan importantes envites: la organización territorial del Estado y el procedimiento legislativo.

En el primer supuesto, se trata de completar el diseño territorial que esbozó (sólo esbozó) la Constitución. La Ley Orgánica referida y el Tribunal han entendido que únicamente puede lograrse este objetivo si la voluntad de la Constitución se ve jurídicamente integrada por normas que buscan su misma finalidad, bien la inicial, bien la recreada por la acción del propio Tribunal Constitucional (problema éste que queda fuera del presente trabajo). 
El segundo supuesto tiene doble alcance. De un lado, preservar algo querido por la Constitución, como es la autonomía de las Cámaras, institución de raíces históricas y congruente con el régimen demoliberal, aunque puedan señalarse algunas excepciones, que no son del caso. Y como esta finalidad de la Constitución quedaría burlada si los reglamentos parlamentarios pudieran ser incumplidos o impuestos por el Ejecutivo, han sido incluidos en el bloque de la constitucionalidad como un complemento de la norma suprema.

Pero, de otro lado, la inserción de los reglamentos parlamentarios en el bloque citado tiene un alcance distinto que se suma al anterior; a saber: los reglamentos parlamentarios son considerados como normas interpuestas entre la Constitución y la ley y regulan el procedimiento legislativo. Y lo regulan a fin de hacer efectivo el principio democrático en dicho procedimiento, que es lo que la Constitución quiere. Por eso, no todo precepto de los reglamentos parlamentarios integra el bloque de la constitucionalidad, sino sólo los que regulan el referido procedimiento.

Las normas de procedimiento legislativo se hallan, las menos, en la Constitución y, en su mayoría, en los mencionados reglamentos. En principio, no parece haber obstáculo a la tesis de que la infracción de un precepto constitucional comporta un vicio de procedimiento determinante -en principio- de la inconstitucionalidad formal de la ley. No se puede concluir de otra manera si se aprueba en Comisión una ley orgánica o una delegación legislativa, o si una ley orgánica es aprobada por mayoría relativa, o, en fin, si se publica una ley sin sanción regia y/o sin refrendo de dicha sanción. Pero no siempre la infracción es tan grave.

Por lo que se refiere a los preceptos de procedimiento legislativo contenidos en los reglamentos parlamentarios, el Tribunal Constitucional decidió incorporarlos al bloque de la constitucionalidad porque (ya lo hemos dicho) son normas interpuestas entre la Constitución y la ley y también porque están hechas para preservar el pluralismo políti$c o$, ya que garantizan la actuación de las minorías en el seno de las Cámaras ${ }^{11}$; es decir, el Tribunal ha interpretado el telos o finalidad de dichas normas y ha considerado que consiste en garantizar el principio democrático en el procedimiento legislativo, y este principio (también lo sabemos) equivale al telos completo de la Constitución.

Sin embargo, la invalidación de una ley por violación de reglamento parlamentario es una consecuencia muy grave y, como dijo hace ya

11 STC 99/1987, de 11 de junio. 
más de veinte años A. GARRORENA, habría de ser la propia jurisprudencia del Tribunal Constitucional la que fuera fijando casuísticamente cuándo ha habido un vicio invalidante y cuándo una mera irregularidad que no debe afectar a la validez formal de la ley así aprobada ${ }^{12}$. En esta casuística han de tenerse en cuenta los criterios que esbozamos a continuación, los cuales, como veremos, y esto es sumamente importante, son aplicables incluso cuando la norma infringida sea del propio texto constitucional.

\section{a) Finalidad de la norma infringida}

Hay unos preceptos constitucionales y reglamentarios más flexibles que otros en orden a la regulación del procedimiento legislativo. Piénsese, por ejemplo, en el incumplimiento, por parte del Senado, del plazo de dos meses que le confiere el artículo 90.2 constitucional para que vete o enmiende el texto remitido por el Congreso de los Diputados; o el envío gubernamental del proyecto de Ley de Presupuestos Generales del Estado después del 30 de septiembre, incumpliendo así el artículo 134.3 de la norma suprema. Tales irregularidades pueden dar lugar a una responsabilidad política, pero no a una sanción jurídica que recaiga sobre la propia ley. Estamos ante mandatos a ciertos órganos constitucionales en cuyo incumplimiento no podemos ver severamente afectadas las garantías de las minorías, salvo que tales retrasos sean muy dilatados, en cuyo caso sí podríamos interpretarlos como una intención de disminuir las mencionadas garantías.

Cosa distinta sería que se intentase tramitar el proyecto de Ley de Presupuestos por el procedimiento de urgencia. Aunque no hay un precepto constitucional que lo prohíba expresamente, sí los hay reglamentarios que lo impiden: el artículo 133.1 del Reglamento del Congreso y el 148.1 del del Senado, ninguno de los cuales incluye la urgencia como una de las especialidades de tramitación de dicho proyecto de ley. A pesar de la diferencia de rango de las normas vulneradas en el caso anterior (constitucional) en comparación con este segundo (reglamentario), es más grave este último supuesto, puesto que impide a la Oposición el estudio detenido del proyecto para su discusión y enmienda, que es la finalidad perseguida por la norma, finalidad que lo que pretende es garantizar una actuación parlamentaria solvente por parte de la Oposición, lo que afecta indudablemente al principio democrático.

12 Garrorena Morales, A., "La sentencia constitucional», Revista de Derecho Político, n. ${ }^{\circ} 11$ UNED, Madrid, 1981, pp. 11 ss. 
b) Posibilidad de sanación del vicio

¿Qué puede decirse del artículo 88 de la Constitución, que ordena al Gobierno que acompañe los proyectos de ley con una exposición de motivos y con los antecedentes necesarios para que las Cámaras puedan pronunciarse sobre ellos? Según el supremo intérprete de la suprema norma, el incumplimiento de este requisito constitucional provoca un defecto de procedimiento subsanable (si la Cámara de que se trate puede exigir al Gobierno la documentación y éste la envía) e incluso convalidable (si la Cámara se da por satisfecha sin la documentación a la que tiene derecho). Pues ¿qué es lo que el precepto constitucional pretende, cuál es su finalidad? Que la Cámara pueda debatir los proyectos de ley con datos suficientes. Es, pues, una garantía para el debate parlamentario, sobre todo para la Oposición, que será la que quiera discutir la corrección del texto enviado por el Gobierno. Pero si la Cámara se da por satisfecha, no hay nada que garantizar. Ahora bien, puede haber parlamentarios individuales que se consideren lesionados por la negativa gubernamental, a los cuales siempre les cabe denunciar el hecho en la Cámara a la que pertenecen para que, a posteriori, la ley pueda ser impugnada por inconstitucionalidad ${ }^{13}$ (y el acto de denegación, recurrido en amparo). Es la interpretación finalista la que rebaja el comentado requisito constitucional hasta hacerlo de cumplimiento facultativo salvo requerimiento parlamentario, puesto que, para concluir este análisis, diremos que, si la Cámara entiende (acaso por la elementalidad del proyecto o por la sencillez de su contenido) que no necesita la documentación mencionada, puede prescindir de ella y no reclamarla, a salvo siempre los derechos comentados de los parlamentarios individuales.

En las líneas anteriores hemos visto un supuesto de vicio procedimental subsanable. Los ejemplos pueden multiplicarse: la repetición de una votación mal hecha, la aceptación de una enmienda rechazada en un principio, y así sucesivamente.

Este segundo criterio (la posibilidad de sanación del vicio) está muy en relación con el anterior. No podemos olvidar la finalidad garantista de las normas de procedimiento. Son, en general, garantías de las minorías frente al Gobierno y a la Mayoría. Buscan el respeto del pluralismo, de la participación de los diversos individuos y grupos, de la libertad de expresión en la Cámara, de la publicidad, etcétera. En ello reside el plus de legitimidad democrática del procedimiento legislativo (parlamentario) sobre el seguido en la aprobación de otro tipo de normas.

${ }^{13}$ STC 108/1986, de 26 de julio. 
Por eso, si las propias minorías aceptan el incumplimiento de un precepto establecido para su garantía, la irregularidad no debe comportar la inconstitucionalidad (al menos, en principio) de la ley. Como dice Paloma Biglino ${ }^{14}$, su aquiescencia, o su falta de denuncia en el momento procesal oportuno, sana la irregularidad cometida. Así lo ha entendido también el Tribunal Constitucional ${ }^{15}$. Hasta cierto punto, podemos decir que son normas constitucionales de eficacia limitada por la finalidad a la que sirven ${ }^{16}$.

\section{c) Principio democrático}

Hay, por consiguiente, vicios de procedimiento más o menos invalidantes del mismo. En palabras del Tribunal Constitucional, un vicio será invalidante cuando altere de modo sustancial el proceso de formación de la voluntad en el seno de la Cámara. Y, como ha estudiado la autora antes citada, lo definitivo es saber si el contenido de la norma infringida puede ser reconducido al principio democrático ${ }^{17}$.

Todo lo cual viene a robustecer cuanto llevamos dicho acerca de la interpretación finalista de este tipo de preceptos. Es preguntándole a éstos el alcance de la garantía que quieren establecer como estaremos en disposición de dictaminar acerca de su carácter ineludible, prescindible o de carencia subsanable.

\subsection{Sentencias interpretativas}

En cuanto al tercer requerimiento de este epígrafe, hemos de decir que, si toda sentencia del Tribunal Constitucional se apoya en una interpretación de la Constitución, las que recaen en un proceso de inconstitucionalidad hacen también una interpretación de la norma infraconstitucional «juzgada». En la mayoría de las ocasiones, el proceso termina con una decisión directa sobre la constitucionalidad o inconstitucionalidad de la ley. Pero en otras ocasiones el Tribunal se pronuncia más matizadamente, apreciando la constitucionalidad de la ley si se la

14 Biglino, P., Los vicios en el procedimiento legislativo, Centro de Estudios Constitucionales, Madrid, 1991, pp. 119 ss.

15 STC 108/1986, citada.

${ }^{16}$ Cfr. Torres del Moral, A., Principios de Derecho Constitucional español, Servicio de Publicaciones de la Facultad de Derecho de la Universidad Complutense, 5 . $^{\text {a }}$ edic., Madrid, 2004, vol. I, p. 196.

17 Biglino, P., Los vicios..., ob. cit., pp. 68-73. 
interpreta en un determinado sentido, o, viceversa, la inconstitucionalidad de una concreta interpretación y la correspondiente licitud constitucional de todas las demás.

El propio Tribunal justifica la emanación de estas sentencias, práctica existente también en otros países, haciendo una interpretación finalista de todo el Ordenamiento jurídico; a saber: éste no puede querer lagunas jurídicas que puedan evitarse. Por eso, el Tribunal acepta como una de sus misiones la de salvar la norma legal hasta donde sea posible y evitar lagunas innecesarias ${ }^{18}$. Es una facultad de muy delicado uso, pero no infrecuente en España. Estamos, pues, ante un mecanismo de confirmación de la supremacía constitucional y, hasta donde se pueda, también de confirmación de la ley, la cual, como producto de las Cortes Generales, representantes directas de la soberanía nacional, goza de una presunción de legitimidad ${ }^{19}$.

\section{INTERPRETACIÓN FINALISTA EN MATERIA DE DERECHOS Y LIBERTADES}

\subsection{Fundamento y naturaleza de los derechos}

Para bien interpretar los preceptos relativos a derechos y libertades, debemos despejar, aunque sea brevemente, el fundamento y naturaleza de los derechos en la Constitución española. Del juego de los artículos 1.1 y 10.1 , parece desprenderse una toma de postura iusnaturalista de la norma suprema, si bien la indicación de que también el respeto a la ley forma parte del citado fundamento introduce una dosis de iuspositivismo no desdeñable. Por último, la apelación a las declaraciones y tratados sobre derechos suscritos por España, que, como tales (los tratados) son Derecho interno (por disposición expresa del artículo 93 constitucional) y la jurisprudencia que, en su caso, hayan propiciado sus textos introduce un elemento iusinternacionalista que debe ser combinado con los otros dos.

A mi manera de ver, el fundamento de los derechos en la Constitución española es plural: antropológico, axiológico, y jurídico-positivo. De estos tres cimientos, nos interesa aquí el segundo, el axiológico, que, como sabemos, reside en los valores superiores enunciados por el artículo 1.1 y los (más o menos del mismo carácter) mencionados en el

18 SSTC 5/1981, de 13 de febrero, y 22/1985 de 15 de febrero.

19 STC 5/1981, citada. Reitera doctrina en SSTC 77/1985, de 27 de junio, y 34/1993, de 18 de noviembre, entre otras muchas. 
10.1: la dignidad de la persona, los derechos inviolables que le son inherentes (es decir, innatos) y el libre desarrollo de su personalidad. La generalidad de la doctrina y la jurisprudencia constitucional española, siguiendo a la Constitución y jurisprudencia alemanas, cifran en la dignidad ese valor fontanal de los derechos. Por eso dice nuestro Tribunal Constitucional que los derechos son "traducción normativa de la dignidad humana ${ }^{20}$ y que ésta es "un minimum invulnerable que todo estatuto jurídico [de los derechos] debe asegurar»" ${ }^{21}$.

A mi modo de ver, el sistema de derechos del Estado social y democrático de Derecho de que España se ha dotado necesita de los tres elementos citados al principio, sin que me parezca teóricamente sostenible el fundamento exclusivamente iusnaturalista que parece desprenderse del párrafo anterior, incluidas las alusiones del propio Tribunal Constitucional al problema. Bien es verdad que éste afirma asimismo que, si bien los derechos responden a un sistema de valores, éstos no pueden entenderse al margen de la Constitución (elemento jurídico-positivo) y que los derechos han de ejercerse siempre conforme al procedimiento jurídicamente establecido (id), siendo, por lo demás, la ley la que puede establecer limitaciones a su ejercicio que respondan a las exigencias de una sociedad democrática (id).

En un texto relevante, el Tribunal dice: "Los derechos fundamentales responden a un sistema de valores y principios de alcance universal que subyacen a la Declaración Universal y a los convenios internacionales sobre derechos humanos, ratificados por España, y que asumidos como decisión constitucional básica, han de informar todo nuestro Ordenamiento jurídico»"22. Luego es su asunción por la Constitución, su constitucionalización por el texto de 1978, la que les confiere una juridicidad cierta.

En cuanto a su naturaleza, digamos sintéticamente, y separándonos parcialmente de las reiteradas expresiones del Tribunal Constitucional, que son derechos públicos subjetivos, elementos esenciales del régimen constitucional, mandatos a los poderes públicos y límites de la soberanía estatal en el orden internacional.

De estos cuatro caracteres nos interesa ahora especialmente el tercero. En efecto, si, por su condición de derechos públicos subjeti-

20 STC 113/1995, de 6 de julio.

21 STC 57/1994, de 28 de febrero.

22 STC 21/1981, de 15 de junio (cursiva mía). Esta doctrina ha seguido una línea constante, no exenta de algún altibajo. Cfr., entre otras muchas, STC 1329/1989, de 17 de julio. 
vos, podemos ver en ellos unos mandatos negativos a los poderes públicos, para que se abstengan generalmente de intervenir en ellos, el constitucionalismo actual ha dotado también a los derechos de unos mandatos positivos que instan a los poderes públicos a actuar en dicho ámbito.

Por eso, como comenta P. HÄBERLE, se viene hablando en Alemania de una política de derechos fundamentales como tarea del Estado. Se trata de una política de prestación, de promoción y de optimización de los derechos, que concierne a todos los poderes públicos, pero, ante todo y sobre todo, al Legislativo, que es el que tiene que desarrollarlos y garantizarlos. Ahora bien, la promoción, optimización, desarrollo y garantía de los derechos no puede acometerse sin una visión finalista de los mismos que oriente dichas actividades.

\subsection{Interpretación teleológica de los derechos o interpretación favorable a la libertad}

Es esta de los derechos y libertades una de las áreas constitucionales en las que tiene mayor aplicación la interpretación teleológica, de conformidad con el principio universalmente admitido in dubio pro libertate, de otra manera conocido como "primado de la libertad", o, lo que es igual,el principio de la interpretación más favorable a la libertad y a la mayor efectividad del derecho, evocado por el Tribunal Constitucional. Pero, aunque no fuera de tan general aceptación, dicho principio vendría exigido por una correcta intelección del artículo 1.1 de la Constitución, pues, si la libertad es un valor superior del Ordenamiento jurídico, toda interpretación que la favorezca sin distorsionar el contenido del precepto, sino ponderando la proporción entre medios y fines, se instala en la misma perspectiva axiológica, finalista, de la Constitución y del resto del Ordenamiento ${ }^{23}$.

El principio anteriormente enunciado tiene su traducción práctica en el adagio jurídico de que los preceptos reconocedores de derechos deben ser interpretados extensivamente, en tanto que los que contienen limitaciones o excepciones deben serlo restrictivamente. Por lo demás, no a otra lógica responde el principio de irretroactividad de las normas sancionadoras desfavorables o restrictivas de los derechos, expresamente reconocido por la Constitución española en su artículo 9.3; tal principio, por el contrario y según el Tribunal Constitucional, sig-

${ }^{23}$ Cfr., entre otras, STC 55/1996, de 28 de marzo. 
nifica una habilitación al legislador para que, en cada supuesto, determine si confiere retroactividad a las normas sancionadoras favorables o extensivas de los derechos, sin perjuicio, en ningún caso, de la seguridad jurídica.

Los derechos fundamentales, dice el mismo Tribunal, son el parámetro conforme al cual deben ser interpretadas todas las normas del Ordenamiento jurídico. La legalidad ordinaria, añade, ha de ser interpretada de un modo finalista, de la forma más favorable para la efectividad de tales derechos y para la maximización de su contenido ${ }^{24}$. Y lo dicho de la legalidad ordinaria se hace extensible a la constitucional. Así lo entiende el Tribunal Supremo, en contrario sentido, al exigir una interpretación restrictiva de las limitaciones de un derecho fundamental, "a fin de no imponer a las personas otras limitaciones en el ejercicio de sus derechos fundamentales que las que exijan el bien común y el respeto de los derechos de los demás" ${ }^{25}$.

Y todo ello es así porque, en un Estado social y democrático de Derecho, en un régimen constitucional normativo, la libertad es la regla, y su limitación, la excepción, que, por este carácter excepcional, ha de estar siempre justificada. Se debe, pues, como dice A. E. PÉREZ LuÑo, reemplazar la concepción estática y defensiva de este principio de interpretación favorable a la libertad por otra positiva y dinámica que busque maximizar y optimizar la eficacia de los derechos ${ }^{26}$.

De esta manera lo entiende, al menos en parte, el Tribunal Europeo de Derechos Humanos al establecer que, cuando la naturaleza del derecho así lo demande, pese sobre los poderes públicos la obligación positiva de crear las condiciones y remover los obstáculos para lograr su efectividad (cfr. art. 9.2 constitucional español). Y lo mismo sucede con los derechos de prestación, como, por ejemplo, el derecho a la instrucción y a la asistencia y defensa de letrado ${ }^{27}$.

${ }^{24}$ STC 34/1983, de 6 de mayo. Reitera doctrina en SSTC 64 y 65/1983, de 21 de julio; 126/1984, de 26 de diciembre; 4, 17, 29, 66 y 172/1985, de 18 de enero, 9 y 28 de febrero, 23 de mayo y 16 de diciembre; 2 y 115/1987, de 21 de enero y 7 de julio; $112 / 1988$, de 8 de junio; 24, 26 y 103/1990, de 15 y 19 de febrero y 4 de junio; $32 / 1991$, de 14 de febrero. La jurisprudencia en esta materia es copiosa y constante.

${ }^{25}$ STS de 11-VII-1980 (Repertorio Aranzadi 2950). La STS de 9-XII-1982 (RA 7542) formula este principio en su versión positiva.

${ }^{26}$ PÉREZ LuÑo, A. E., Derechos humanos, Estado de Derecho y Constitución, ob. cit., pp. 315-316.

${ }_{27}$ Sentencia del Tribunal Europeo de Derechos Humanos, de 9-IV-1984, caso Goddi. 


\subsection{Eficacia de los derechos en las relaciones jurídico-privadas}

Y ha sido la aplicación de este principio de interpretación favorable a la libertad uno de los factores que más ha contribuido y está contribuyendo a la extensión (efecto irradiación) de la eficacia de los mismos a las relaciones entre particulares, eficacia frente a terceros o eficacia en las relaciones jurídico-privadas (Drittwirkung para los alemanes), si bien en estas relaciones no rigen los mismos estándares ni exigencias que en la actuación del Estado. Esta eficacia, también llamada horizontal, no se predica de todos los derechos, pero sí de algunos, precisamente de aquellos en los que el riesgo puede provenir tanto de los poderes públicos como de las fuerzas sociales y económicas de índole privada. Porque una interpretación finalista de la Constitución lleva a la conclusión de que, cuando los ataques a los derechos provengan de personas privadas (sean físicas o jurídicas), un Estado social y democrático de Derecho no puede olvidar que la Constitución existe como garantía de la libertad, y, por tanto, se encuentra habilitado (y en ciertos casos, obligado) para actuar a fin de hacer efectiva dicha garantía en la realidad jurídica vivida, de la cual no puede desentenderse como hacía el Estado liberal.

El corolario lógico es que, como dice R. ALEXY, esos valores expresados en los derechos constitucionales proporcionan directrices e impulsos para la legislación, para la administración y para la justicia. La lesión puede haberla producido un particular, pero, si el sujeto pasivo no obtiene una adecuada satisfacción del juez, puede entenderse que también éste está vulnerando su derecho en segundo grado, lo que abre, en España, la vía del recurso de amparo ante el Tribunal Constitucional.

Seguramente es el mencionado el efecto más importante que ha proporcionado la interpretación teleológica en materia de derechos y libertades. En España, tras unos titubeos, el Tribunal Constitucional se ha ido inclinando paulatinamente a favor de la tesis que sostenemos, con los matices correspondientes. Ha sido así porque este Alto Tribunal ha interpretado que, si bien el artículo 53.1 expresa que los derechos fundamentales vinculan a los poderes públicos, no excluye (interpretación finalista, porque se trata de llevar al máximo el fin para el que la norma fue instituida) otros posibles destinatarios de su mandato: «En un Estado social de Derecho no puede sostenerse con carácter general que el titular de tales derechos no lo sea en la vida social ${ }^{28}$, de mane-

${ }^{28}$ STC 18/1984, de 7 de febrero. 
ra que, en alguna medida, siempre tienen dicha eficacia ${ }^{29}$ en esta área de la realidad normalmente regulada por el Derecho privado, el cual, en esto, queda impregnado de constitucionalidad precisamente por la supremacía del texto fundamental.

En la legislación, en la jurisprudencia y en la propia Constitución se encuentran muestras elocuentes de esta eficacia horizontal de los derechos constitucionales:

a) Unas veces se trata de garantías frente a todos (y, por tanto, también frente a los particulares), como, por ejemplo, la no obligatoriedad de declarar sobre la ideología, religión o creencia propia (art. 16.2), o la prohibición de tribunales de honor en las organizaciones profesionales (art. 26).

b) Otras veces estamos en presencia de una garantía que la Constitución eleva a categoría de derecho, como la cláusula de conciencia y el secreto profesional en la comunicación pública.

c) En la mayoría de los casos, lo que se produce es una colisión de derechos y su correspondiente limitación recíproca, que tiene que ponderar la autoridad judicial.

La jurisprudencia ha desenvuelto otros ámbitos de dicha eficacia, sobre todo el sociolaboral. He aquí algunas tesis jurisprudenciales:

- Ilicitud del cierre empresarial como respuesta a una huelga legítima ${ }^{30}$.

- Vigencia de la libertad de expresión en el seno de la empresa ${ }^{31}$, como también la hay en las asociaciones ${ }^{32}$ y en los partidos políticos ${ }^{33}$.

- Vigencia del derecho a la intimidad personal dentro de la empresa $^{34}$.

- Vigencia de la presunción de inocencia en el régimen de despidos, pesando sobre el empresario la carga de la prueba acerca de su procedencia ${ }^{35}$.

${ }^{29}$ STC 114/1995, de 6 de julio.

30 STC 72/1982, de 2 de diciembre.

31 STC 88/1985, de 19 de julio.

32 STS de 24-III-1992 (RA 2283).

33 STC 56/1995, de 6 de marzo.

34 STS de 10-III-1990 (RA 2045).

35 Cfr., por todas, STC 37/1985, de 8 de marzo. Y, entre las sentencias del Tribunal Supremo, también por todas, cfr. STS de 18-X-1985 (RA 5163). 
- Garantía de indemnidad, esto es, nulidad de todo despido producido con violación de la igualdad ${ }^{36}$, de la libertad sindical ${ }^{37} \mathrm{y}$, en general, de cualquier derecho fundamental ${ }^{38}$.

- Limitación de la libertad empresarial por el principio de igualdad $^{39}$, muy especialmente por la igualdad entre hombre y mujer.

No se agotan aquí las muestras de la mencionada eficacia. Sean, por ejemplo, la igualdad de los hijos y de los cónyuges (arts. 39.2 y 32.1 de la Constitución), el mismo principio de igualdad como límite de la libertad de testar ${ }^{40}$, o la aplicación de la presunción de inocencia en el procedimiento de expulsión del miembro de una asociación, o del socio de una cooperativa. Baste, sin embargo, con lo expuesto ${ }^{41}$.

\subsection{Justificación suficiente de las limitaciones y restricciones de los derechos}

Como en un Estado social y democrático de Derecho la libertad es la regla y su limitación la excepción, ésta debe de estar sólidamente justificada, hacerse por ley y respetar el contenido esencial del derecho en cuestión. Lo dicho está ampliamente explicado por el Tribunal Constitucional: "Cuando se coarta... el libre ejercicio de los derechos reconocidos por la Constitución, el acto es tan grave que necesita una especial causalización y el hecho o conjunto de hechos que lo justifican deben explicitarse con el fin de que los destinatarios conozcan las razones por las cuales su derecho se sacrificó y los intereses a los que se sacrificó ${ }^{42}$.

El Convenio Europeo de Derechos Humanos establece, de manera casi uniforme en cada precepto, que el ejercicio de la libertad o del derecho correspondiente puede ser sometido por ley a ciertas restricciones "que constituyan medidas necesarias, en una sociedad democráti-

${ }^{36}$ Cfr., por todas, STC 38/1081, de 23 de noviembre.

37 Misma STC, que inicia una jurisprudencia uniforme. Cfr. STS de 24-XII-1990 (RA 9828).

38 STC $47 / 1985$, de 27 de marzo, entre otras muchas.

39 STS de 5-II-1985, (RA 602), entre otras muchas.

40 STC 27/1982, de 24 de mayo.

${ }^{41}$ Cfr., entre la abundante bibliografía, LóPEz AguiLAR, J. F., Derechos fundamentales y libertad negocial, Ministerio de Justicia, Madrid, 1990.

42 STC 26/1981, de 17 de julio. Reitera doctrina en SSTC 62/1982, de 15 de octubre, 50/1995, de 23 de febrero, 49 y 54/1996, de 26 de marzo, y 67/1997, de 7 de abril, entre otras muchas (cursiva mía). 
ca», para la seguridad nacional, la defensa del orden, la protección de la salud o de la moral, etcétera. Conceptos que han motivado una jurisprudencia casuística muy ponderada en torno a este problema. De manera que la limitación debe estar adoptada por ley y su necesidad se mide por el metro de una sociedad democrática ${ }^{43}$. Y por abundar en el concepto de interpretación teleológica, baste con evocar el artículo 18 del referido Convenio, el cual prohíbe que esas restricciones de los derechos y libertades sean aplicadas con una finalidad distinta de aquella para la que fueron previstas.

Ahora bien, no todo acto de los poderes públicos limitativo de los derechos es descalificable a priori. En relación armónica con los anteriores criterios debemos poner el principio, desenvuelto por el Tribunal Constitucional, de presunción de legitimidad de los actos emanados de los poderes públicos, inexcusable en toda sociedad democrática, máxime si procede del Parlamento, que representa a la soberanía nacional ${ }^{44}$.

En conclusión, y como ha comentado R. NARANJO, la limitación de los derechos constitucionales se lleva a cabo por la necesidad de coordinar su protección con otros bienes y derechos constitucionalmente reconocidos, pero su fuerza normativa y su valor dentro del Ordenamiento exige que su restricción esté debidamente justificada conforme al principio de proporcionalidad ${ }^{45}$. Por tanto, la resolución judicial acerca de alguna medida delimitadora de un derecho fundamental ha de hacer un juicio de proporcionalidad, en el que se compruebe si tal medida persigue un fin legítimo, si es adecuada y proporcionada a ese fin, si es necesaria y si es legal|46.

\section{INTERPRETACIÓN TELEOLÓGICA E IGUALDAD}

En los primeros estudios sobre la Constitución española, una posición de los comentaristas destacó la especial protección constitucional de que goza el artículo 14, que proclama el principio clásico de igualdad

${ }^{43}$ STEDH de 25-III-1983, caso Silver y otros. La sentencia desenvuelve y reitera la doctrina establecida en otras muchas anteriores: SSTEDH de 7-XII-1976, caso Handyside; de 6-IX-1978, caso Klass y otros; de 26-IV1979, caso "Sunday Times», etc.

44 STC 66/1985, de 23 de mayo.

45 NARANJO DE LA CRUZ, R., Los límites de los derechos fundamentales en las relaciones entre particulares: la buena fe, Centro de Estudios Políticos y Constitucionales, Madrid, 2000.

${ }^{46}$ Cfr., entre otras muchas, SSTC 55 y 207/1996, de 28 de marzo y 16 de diciembre. 
jurídica o ante la ley («Todos los españoles son iguales ante la ley, sin que pueda prevalecer discriminación alguna...") frente a los principios de política social y económica (capítulo III del Título I) y frente al artículo 9.2, que se halla en el Título Preliminar y que alude a la consecución de una igualdad y una libertad reales y efectivas. Otros, por el contrario, intentaron poner de relieve la importancia de esa ubicación del artículo 9.2 entre los principios fundamentales del régimen que instaura la Constitución, viniendo a ser — se dijo- una verdadera cláusula de transformación de la sociedad en manos de los poderes públicos (P. LUCAS VERDÚ).

A mi juicio, no podemos prescindir de ninguno de dichos preceptos, sino interpretarlos integradoramente. El legislador no puede adoptar una concepción formalista de la igualdad como equivalente a la generalidad de la ley, sino que está obligado a atender los elementos diferenciadores de categorías y grupos de ciudadanos, hasta llegar excepcionalmente a la ley singular si ello fuere preciso. Como ha puesto de manifiesto J. A. MonTILLA MARTOS ${ }^{47}$, en un Estado social y democrático de Derecho, la ley singular no es un fenómeno patológico, sino a veces una exigencia de su carácter interventor.

Pero tampoco puede hacerse de esas leyes singulares la regla y de las generales la excepción: se arruinaría el tráfico jurídico y, a la postre, la consecución de ese fin político perseguido. En un Estado social y democrático de Derecho, el legislador está orientado a la igualdad real y efectiva como fin político. Pero atemperará el ritmo a las exigencias de la seguridad y del tráfico jurídico, a las posiciones legítimamente adquiridas por ciertos ciudadanos, a los derechos constitucionalmente consagrados, a otros bienes y fines tutelados; en conclusión, a todos y cada uno de los principios informadores del Estado de Derecho; $y$, entre ellos, a la igualdad jurídica.

De otro lado, el Tribunal Constitucional, interpretando que la finalidad querida por la Constitución al elevar la igualdad a valor superior del Ordenamiento jurídico es ampliar su contenido y alcance hasta donde se pueda sin vulnerar tal Ordenamiento, ha hecho varias operaciones altamente relevantes a este respecto:

1. Ha incluido en la igualdad ante la ley del artículo 14 , la igualdad en la ley, exigiendo, por tanto, que la ley misma (o cualquier norma jurídica (aquí ley es sinónimo de norma, no de un tipo de fuente determinado) trate de mantener o de alcanzar la igualdad

47 Montilla Martos, J. A., Las leyes singulares en el Ordenamiento constitucional español, Civitas, Madrid, 1994. 
como fin político del régimen. Si se trata de mantenerla porque ya la hay, la ley debe ser general y no hacer acepción de personas ni de grupos. Si se trata de alcanzarla, o sea, de remediar una situación de desigualdad, la ley puede (¿también debe?) introducir diferentes tratamientos jurídicos para compensar esa desigualdad de base.

2. El Tribunal Constitucional español, como también el Europeo de Derechos Humanos, ha utilizado desde el principio, para enjuiciar este tipo de normas, el canon de la relevancia jurídica del elemento diferenciador. En efecto, no se busca (elemento teleológico) comprobar la diferencia entre dos supuestos de hecho, sino que se debe apreciar si tal diferencia debe tener como consecuencia un trato jurídico distinto desde el punto de vista o razón de ser (es decir, desde el punto de vista del fin) de la norma misma en cuestión.

3. Pues bien, en este orden de consideraciones, el Tribunal Constitucional ha establecido unos criterios generales que debemos retener por ser sumamente pertinentes para nuestro estudio:

a) Los poderes públicos deben promover los valores superiores del Ordenamiento jurídico. No se trata sólo de respetar los principios técnico-jurídicos del artículo $9.3^{48}$, ni sólo la igualdad formal del artículo 14, sino también la igualdad real y efectiva del artículo 9.2, la igualdad de los individuos y de los grupos en los que aquéllos se integran ${ }^{49}$. Este último precepto, dice el Tribunal (acaso, a mi entender, un tanto hiperbólicamente) es proyección del carácter social del Estado y la efectividad de la igualdad y de la libertad que en él se propugna está vinculada al objetivo de garantizar un bienestar material generalizado ${ }^{50}$.

b) Todo ello requiere de los poderes públicos actuaciones positivas para remover obstáculos y para promover condiciones (palabras idénticas a las del artículo 9.2 constitucional), y cauces institucionales para esa efectividad de la libertad y de la igualdad y para la solución de los conflictos sociales ${ }^{51}$.

${ }^{48}$ Son los principios, como el de legalidad, el de jerarquía normativa, etc., básicos en un Estado formal de Derecho.

${ }^{49}$ STC $27 / 1081$, de 20 de julio.

50 STC 3/1983, de 25 de enero.

51 SSTC 6 y 11/1981, de 16 de marzo y 8 de abril. 
c) Por tanto, dice el mismo Tribunal, en línea con el Europeo de Derechos Humanos, el legislador puede, sin reducirse a la pura igualdad ante la ley, introducir conscientemente ciertas diferencias de tratamiento jurídico con la finalidad de conseguir esa igualdad real y efectiva ${ }^{52}$. El criterio más utilizado por ambos tribunales a este respecto es el de la proporcionalidad entre la finalidad constitucionalmente lícita de propiciar una igualdad real y efectiva y los medios empleados para ello. El Tribunal Europeo de Derechos Humanos sostiene que ciertas desigualdades de derecho tienden razonablemente a corregir desigualdades de hecho $y$, por ende, a conseguir una igualdad real. En este ámbito se inscribe, por ejemplo, la acción positiva o afirmativa en beneficio de la igualdad real de la mujer ${ }^{53}$.

d) EI Derecho laboral se basa en este principio político de la igualdad (la igualdad como tarea de los poderes públicos, como finalidad del Estado social), puesto que introduce diferencias jurídicas que tratan de corregir y de compensar las desigualdades sociales preexistentes ${ }^{54}$.

e) En función de la igualdad real y efectiva no se puede dar lugar a resultados contrarios a los derechos y libertades constitucionales, ni pueden producirse normas contrarias a otros preceptos o principios de la Constitución, como tampoco se puede con tal motivo producir diferencias discriminatorias ${ }^{55}$. He aquí un límite de la interpretación teleológica en materia de igualdad, acaso el más relevante.

f) Por último, el Tribunal Constitucional valida también las leyes singulares si responden a situaciones jurídicas de igual índole (es decir, singulares) y son medidas finalistas razonables $y$ proporcionadas a los supuestos de hecho sobre los que se proyectan $^{56}$.

Pero acaso lo más interesante de esta línea jurisprudencial es que ambos mencionados tribunales han entendido que el principio jurídico

52 SSTC 27 y 34/1981 de 20 de julio y 10 de noviembre; 3/1983, citada; 24 y 93/1984, de 20 de febrero y 16 de octubre; 98/1985, de 29 de julio, y 18/1988, de 16 de febrero, etc.

53 Por todas, STC 216/1991, de 14 de noviembre.

54 STS de 19-II-1985 (RA 666).

55 SSTC 34/1981, de 10 de noviembre, y 75/1983, de 3 de agosto.

56 STC 166/1986, de 19 de diciembre. 
de la igualdad (o igualdad ante la ley) da cobertura jurídica al principio político de la igualdad (la igualdad en la ley, la igualdad como tarea del Estado social). Su trascendencia es extraordinaria, pues el primero de estos principios está protegido por recurso de amparo y, por consiguiente, cualquier ciudadano que se vea discriminado por una norma, salvo que ésta sea una ley formal, puede instar la tutela judicial ordinaria invocando el artículo 14, interpretado a la manera dicha, y, en su caso, el amparo de la jurisdicción constitucional, corrigiéndose así la imposibilidad de invocar el artículo 9.2, que no es susceptible de amparo. De tal manera se gana así mucho en protección de los ciudadanos y en la lucha contra la discriminación, aunque sea al precio de llevar el contenido del artículo 9.2 hasta el 14 mediante la descrita interpretación teleológica. El propio Tribunal Constitucional dice en alguna ocasión que interpreta el artículo 14 de acuerdo con las exigencias del Estado social, y ya sabemos que él mismo entiende que el precepto que manifiesta dicho carácter social del Estado es el 9.257.

\section{LA INTERPRETACIÓN TELEOLÓGICA DEL TRIBUNAL CONSTITUCIONAL ESPAÑOL ACERCA DEL DERECHO DE PARTICIPACIÓN POLÍTICA.}

El artículo 23.2 de la Constitución reconoce a los ciudadanos el derecho a acceder, en condiciones de igualdad, a las funciones y cargos públicos, con los requisitos que señalen las leyes. Hay que entender que estas expresiones están preñadas de significado político y son expresivas todas ellas del derecho fundamental de participación política. Por el contrario, el artículo 103.3 habla del acceso a la función pública, en singular, aludiendo a la incorporación de personas al servicio de la Administración; por eso está ubicado en el Título IV y elude la palabra derecho.

Apenas nos detendríamos en este derecho aquí si no fuera por la interpretación extensiva, teleológica, que de él ha hecho el Tribunal Constitucional. El acceso a los cargos públicos — vamos a ceñir nuestra perspectiva, como también hace el Tribunal, a los cargos electivos- es una simple consecuencia del derecho de sufragio pasivo. Pero el supremo intérprete de la Constitución entiende que está también comprendido en él, con todas las garantías pertinentes, el derecho a desempeñar dichos cargos en condiciones de igualdad y adecuadas a la

57 Torres del Moral, A., "¿Qué igualdad?», Revista de Derecho Político, n. ${ }^{\circ} 46$, UNED, Madrid, 1998, pp. 77-102. 
finalidad a la que sirven, y a permanecer en ellos sin ser removidos sino por causas legales ${ }^{58}$. (El sujeto de este derecho es, lógicamente, el ciudadano, en ningún caso el partido político ${ }^{59}$ ).

En segundo lugar, los representantes tienen derecho a desempeñar su cargo sin menoscabo por parte de los órganos de dirección del ente en que se encuadran. El Tribunal ya había advertido que en esto está en juego no sólo el derecho del representante mismo, sino el del propio electorado a que su representante permanezca en el cargo y pueda desempeñarlo idóneamente ${ }^{60}$. El Tribunal Supremo ha secundado por completo este planteamiento.

Por tanto, el derecho que estudiamos, haciendo una interpretación finalista del mismo y buscando en la norma lo que ésta quiere decir en última instancia (que no su mera literalidad de acceso a los cargos públicos) incluye, entre otros:

a) El derecho del representante a que le sean admitidas las iniciativas (preguntas, interpelaciones y mociones) y las enmiendas que presente, siempre de conformidad con el Reglamento de la Cámara o Corporación ${ }^{61}$.

b) El derecho a que las comisiones que se creen en los Ayuntamientos y Diputaciones Provinciales sean respetuosas con la proporcionalidad de escaños existente entre los grupos políticos, y a formar parte, como mínimo, de una de ellas ${ }^{62}$.

c) El derecho a participar como elector de y elegible a los cargos parlamentarios ${ }^{63}$.

d) El derecho a que se convoque el pleno del Ayuntamiento a fin de que se pueda votar una moción de censura o para cualquier otra función propia del mismo, salvo que no haya realmente asuntos que tratar ${ }^{64}$.

58 SSTC 24/1990, de 15 de febrero; 7/1992, de 16 de enero; 30/1993, de 25 de enero; 7/1994, de 3 de marzo; 45 y 104/1005, de 14 de febrero y 3 de julio.

59 SSTC $36 / 1990$ y $167 / 1991$, citadas.

60 SSTC 363 y 365/1993, de 13 de diciembre, y 60/1994, de 28 de febrero.

61 SSTC 23 y 205/1990, de 15 de febrero y 13 de diciembre; 81/1991, de 22 de abril; 225/1992, de 14 de diciembre; 95/1994, de 21 de marzo, y 118/1995, de 17 de julio.

62 SSTC 214/1990, de 20 de diciembre, y 30/1993, de 25 de enero. STS de 7-VI1991 (RA 7691).

63 STC 149/1990, de 1 de octubre.

64 SSTS de 19-XII-1990, 27-IV-1993, 21-V-1993 y 8-VII-1993 (RRA 623, 3121, 3962 y 5629 , respectivamente). 
Lo que el Tribunal Constitucional ha hecho en los últimos años ha sido apoyarse en esta doctrina para poder enjuiciar actos internos de las Cámaras parlamentarias. En efecto, sin llegar a desechar la inveterada doctrina de los interna corporis acta, conforme a la cual la autonomía parlamentaria protege los actos internos de la Cámara haciéndolos irrecurribles y no fiscalizables, el Tribunal recaba para sí mismo el amparo de los derechos que integran el estatuto del parlamentario argumentando que dichos derechos - uso de la palabra, presentación de enmiendas, pertenencia a comisiones, derecho de voto...- no son sino especificaciones del derecho fundamental al cargo público ${ }^{65}$.

En conclusión, haciendo una interpretación extensiva y teleológica del derecho de participación política y llevando a sus últimas consecuencias cuáles son las exigencias de una idónea, pluralista y democrática representación política, el Tribunal ha construido un macroderecho con el artículo 23.2 de la Constitución, que, en un principio, ni siquiera se sospechaba que pudiera hacerse así.

$$
\text { *** }
$$

Podríamos extendernos en otros pasajes constitucionales en los que el Alto Tribunal español ha hecho también interpretaciones finalistas, o en los que las podríamos hacer nosotros (por ejemplo, en el estatuto jurídico de la Corona, en la responsabilidad política individual de los ministros, etc.), pero creo que es suficiente lo expresado en las páginas precedentes para hacernos una idea aproximada del alcance de este tipo de interpretación, que, de todos modos, debe ser utilizado con prudencia y mano maestra.

65 SSTC 23, 119, 205 y 214/1990, de 15 de febrero, 21 de junio, y 13 y 20 de diciembre; 74 y 81/1991, de 8 y 22 de abril. El Tribunal se apoya en sentencias anteriores ( 101 y 122/1983, de 18 de noviembre y 16 de diciembre, y 8/1985, de 25 de enero), que, sin embargo, no eran tan explícitas en la faceta que estudiamos. Cfr. también STC 76/1994, de 14 de marzo, y 124/1995, de 18 de julio. 